\title{
Expert Communication and the Self-Defeating Codes of Scientific Ethics
}

\author{
Hugh Desmond \\ KU Leuven \\ University of Antwerp
}

Published in The American Journal of Bioethics

Just as the COVID-19 pandemic has laid bare the limitations of medical codes of ethics (London 2021), it has also laid bare the limitations of scientific codes of ethics, particularly with regard to expert communication. This commentary will argue that scientific experts may face a fundamental dilemma between prioritizing actionability and prioritizing scientific transparency in their communications, and moreover, that this dilemma has an ethical dimension that should be anticipated in ethical guidelines for scientists.

The crux of the trade-off facing scientific experts is the following. If the expert prioritizes actionability by downplaying scientific uncertainty, this can indeed spur the public to make behavioral changes. However, if the expert's statements turn out to be wrong afterwards, the trustworthiness of the scientist and indeed of the scientific community as a whole may suffer. The risk is that the public perceives experts to be paternalistic, where not all scientific details are communicated in order to avoid undesirable patterns of behavior. London's example of Dwayne "The Rock" Johnson, who communicated that "the plasma that's in your blood can literally save lives" (London 2021, 11), is a case in point of where actionability was prioritized over scientific transparency. Risks to future individual or collective trustworthiness may thus prevent a prudent scientific expert from prioritizing actionability too much over scientific transparency.

Yet there is no easy way out, because a scientific expert can also be too scrupulous in conveying what the scientific community does not yet know or is not yet certain about. Newton once compared himself to a child collecting pebbles on the beach, at the edge of a great ocean of truth yet to be discovered. A similar epistemic humility from a scientific expert would not only lead to the expert being ignored in the crowded space of punditry and social media, it would also not help in persuading the public and policy-makers to change courses of action, especially when these involve costly mitigation measures such as has been the case in the COVID-19 pandemic.

The existence of this fundamental trade-off is not always recognized by those who claim to speak "in the name of science only". Yet even when, for instance, meteorologists provide actionable advice to the public, also they are making trade-offs between actionability and transparency. The trade-off is not felt acutely since the cost of wrongly forecasting the weather is usually not steep; however, the trade-off is vividly present when uncertain but potentially catastrophic scenarios threaten. These are moments when high-confidence scientific predictions are in great public demand but short supply by scientists. The public will want to know, as far as is possible, how much should be invested in costly mitigation measures. Experts are then faced with a trade-off between meeting the public's need for actionable advice (whether to embark on mitigation or not) versus communicating the uncertainty of the scientific state-of-the-art. This trade-off has long been recognized in context of the debate about climate change, where scientists have downplayed some scientific uncertainty for the sake of 
actionability with regards to mitigation measures (and out of fear that climate skeptics would seize on any communication of uncertainty: Oreskes 2004).

Doing this in the wrong way not only risks damage to perceived trustworthiness; extra caution is required when the costs of mitigation involve active harm. To illustrate this, consider the issue of school closures during the pandemic. On the one hand, schools represent a daily congregation of a large number of people who are not always capable of maintaining social distancing, and hence keeping schools open represents a danger of furthering the transmission of the virus. This danger is somewhat mitigated by observations that young children do not seem to be potent vectors of transmission (Lee and Raszka 2020); nonetheless, despite this mitigation, school closures do, in themselves, help contain the viral transmission. Yet, on the other hand, the mortality rate for minors and young adults remains very low, and moreover, school closures imply unknown, but perhaps significant and irreversible costs in terms of cognitive and social development. These costs are suffered most by children from lower socioeconomic strata (Armitage and Nellums 2020; Lancker and Parolin 2020). This implies a genuine dilemma between prioritizing the well-being and development of children, and doing as much as possible to depress the viral replication rate, especially for the sake of the older segment of the population.

Despite the complexity of the issue, at such moments the scientific community is not necessarily given the option to refuse to give expert advice. Action is needed, and advice is demanded. Moreover, if non-experts would fill the informational void instead, it could conceivably even be a dereliction of duty for expert scientists to refuse to give advice. So, while some aspects of the issue of school closures clearly go beyond the competences of virologist or epidemiologists, the latter may nonetheless be demanded for actionable advice on the issue. This puts them in a difficult position. How should experts deliberate in crafting their message?

Despite expert advice being one of the most important services provided by the scientific community to society as a whole, the ethical dimension of expert communication has gone almost entirely unrecognized. It is not recognized by scientists who claim to speak in the name of science only; more importantly, it is not recognized by major codes of conduct for scientists. These codes define the duties of scientists with regards to research and publication, supervision and mentoring, peer review and editing (ALLEA 2017; NAS 2017). However, they are almost without exception entirely silent on what moral norms should guide the scientist when acting in the capacity of expert. In one of the few normative documents acknowledging the issue, the IAC-IAP Report (IAC-IAP 2012), one can find the stipulation that:

Researchers should resist speaking or writing with the authority of science or scholarship on complex, unresolved topics outside their areas of expertise. Researchers can risk their credibility by becoming advocates for public policy issues that can be resolved only with inputs from outside the research community. (IAC-IAP 2012, p. 27)

The IAC-IAP document, in effect, advises scientists to act in a "value-neutral" capacity, and thus not to be influenced in any way by extra-scientific values (Douglas 2009). However, what the COVID-19 pandemic has shown is that, when the public need is sufficiently urgent, scientists have no option but to transgress this boundary and to speak with authority on unresolved topics and on public policy issues. This was especially true in the early weeks of the pandemic, when few outside the scientific community had any knowledge of the SARS$\mathrm{CoV}-2$ virus, and when there was a palpable sense of an almost existential threat.

This upshot is a moral loophole for some scientific experts being unduly influenced by particular societal or individual values, thus endangering the credibility and integrity of the scientific community as a whole. And in fact, without naming names, it does seem safe to state that expert communication during the COVID-19 pandemic has not always achieved the 
prudential ideal. For instance, initially the effectiveness of face masks was downplayed, but it later turned out that this communication was crafted with the intention of preventing panicbuying: this would be an example of how actionability was inappropriately prioritized over scientific transparency. Other times, certain statistics were inappropriately emphasized in the name of scientific transparency: thus, for instance, the relatively low number of actual deaths from COVID (compared to the total mortality in society) was sometimes emphasized to counter perceived fear-mongering. While true, the communication is nonetheless misleading, because it would also be crucial to communicate what the total number of deaths could be if the virus were left to spread unchecked.

In sum, the absence of what can be called "the ethics of expert communication" represents an important lacuna in codes of scientific ethics. Codes of conduct for scientists should be expanded to include a set of guidelines to help them in future emergencies to craft their expert communications with prudence, in a way that reflects both the scientific state-ofthe-art, provides the wider community with reasonably actionable advice, and yet avoids the worst charges of paternalism or lack of trustworthiness.

This would represent an expansion of the traditional concept of scientific service, where the scientist is conceived to conduct a "disinterested" search for truth and understanding (Desmond 2020). In precarious and highly uncertain epistemic environments, the scientist is called upon to directly serve their community and to advise the public what to do. This is a different service ideal than that of truth or understanding.

An ethics of expert communication would also represent an expansion of the values and principles commonly identified by codes of conduct - such as "honesty" or "respect" (ALLEA 2017). First of all, the value of "care" is missing here, or some other care-like value that is oriented towards the interests of the community. Further, in the ethics of expert communication, values such as honesty would assume new dimensions: honesty in expert communication entails publicly acknowledging the trade-off between actionability and scientific transparency. Ethical expert communication would thus strengthen and elevate public democratic discourse, and help avoid the charges of paternalism and technocracy often leveled at experts.

\section{References}

ALLEA, All European Academies. 2017. The European Code of Conduct for Research Integrity. http://www.allea.org/wp-content/uploads/2017/04/ALLEA-European-Codeof-Conduct-for-Research-Integrity-2017.pdf.

Armitage, Richard, and Laura B. Nellums. 2020. "Considering Inequalities in the School Closure Response to COVID-19." The Lancet Global Health 8 (5): e644. https://doi.org/10.1016/S2214-109X(20)30116-9.

Desmond, Hugh. 2020. "Professionalism in Science: Competence, Autonomy, and Service." Science and Engineering Ethics 26 (3): 1287-1313. https://doi.org/10.1007/s11948019-00143-x.

Douglas, Heather. 2009. Science, Policy, and the Value-Free Ideal. Pittsburgh, PA: University of Pittsburgh Press.

IAC-IAP. 2012. "Responsible Conduct in the Global Research Enterprise: A Policy Report." https://www.interacademies.org/publication/responsible-conduct-global-researchenterprise. 
Lancker, Wim Van, and Zachary Parolin. 2020. "COVID-19, School Closures, and Child Poverty: A Social Crisis in the Making." The Lancet Public Health 5 (5): e243-44. https://doi.org/10.1016/S2468-2667(20)30084-0.

Lee, Benjamin, and William V. Raszka. 2020. "COVID-19 Transmission and Children: The Child Is Not to Blame.” Pediatrics 146 (2). https://doi.org/10.1542/peds.2020004879.

London, Alex John. 2021. "Self-Defeating Codes of Medical Ethics and How to Fix Them: Failures in COVID-19 Response and Beyond." The American Journal of Bioethics 21 (1): 4-13. https://doi.org/10.1080/15265161.2020.1845854.

NAS, (National Academies of Sciences, Engineering, and Medicine). 2017. Fostering Integrity in Research. Washington, D.C.: National Academies Press. https://doi.org/10.17226/21896.

Oreskes, Naomi. 2004. "The Scientific Consensus on Climate Change.” Science 306 (5702): 1686-1686. https://doi.org/10.1126/science.1103618. 